\title{
Crisis urbana y respuesta institucional en dos megaciudades. Lecciones del manejo de la devastación sísmica en las ciudades de México y Los Ángeles*
}

\section{Aseem Inam**}

\begin{abstract}
Apoyado en un marco analitico derivado tanto de la teoria institucional como de la teoría de la planeación urbana, este estudio examina los resultados de dos programas creados para restablecer el orden y la estabilidad después de una situación de crisis urbana. Éstos son: el Programa de Renovación Habitacional Popular en la Ciudad de México, establecido luego del terremoto de 1985, y el Programa Ghost Town establecido en la ciudad de Los Ángeles, Califormia, después del terremoto de 1994. Ambos han sido encomiados por su accionar rápido, su financiamiento masivo, el mejoramiento de las condiciones preexistentes, la participación comunitaria, y la coordinación institucional. El argumento principal de este estudio es que las intituciones de planeación urbana en ambas ciudades fueron efectivas durante la crisis provocada por los sismos, principalmente porque se apoyaron en rutinas institucionales: un tipo de procedimiento que suele ser denostado o subestimado porque tiene la reputación de ser extremadamente burocrático. Las instituciones de planeación en la Ciudad de México y Los Ángeles respondieron con efectividad porque fueron capaces de adaptar rutinas institucionales, en forma rápida y eficiente, a circunstancias imprevistas y dramáticas. Planteado como un estudio de caso, este análisis se propone clarificar y explicar la dinámica de la planeación urbana en un contexto de crisis de dos maneras: Primero, los estudios de caso demuestran que un análisis institucional explícito y sistemático ayuda a entender mejor qué elementos dan buenos resultados en materia de planeación urbana, y por qué. Segundo, el análisis institucional muestra bajo qué condiciones pueden servir las rutinas institucionales como herramientas poderosas y efectivas para resolver situaciones imprevistas sin importar el contexto sociopolitico dominante.
\end{abstract}

Palabras clave: crisis urbana, respuesta institucional, rutinas institucionales, planeación urbana, Ciudad de México, Los Ângeles.

Fecha de recepción: 28 de enero de 2000.

Fecha de aceptación: 9 de marzo de 2001.

\section{Introducción}

¿Qué tan efectivas son las instituciones de planeación urbana frente a la complejidad, incertidumbre y cambio acelerado que caracterizan

\footnotetext{
* En este trabajo participó Francisco Lara Valencia como asistente y traductor.

** Profesor de Planeación Urbana de la Universidad de Michigan, Ann Arbor, Estados Unidos. Correo electrónico: aseem@umich.edu
} 
la vida cotidiana en las megaciudades contemporáneas? Éste es un estudio que explora las formas en que responden a una situación de crisis las instituciones de planeación urbana en dichas megaciudades; es decir, cómo hacen para reestablecer la normalidad después de una situación caracterizada por su intensa complejidad, elevada incertidumbre y celeridad de cambio. Las megaciudades son enormes y constituyen complicados crucigramas urbanos, no sólo porque albergan poblaciones que rebasan diez millones de individuos, sino también porque plantean problemas altamente complejos e inéditos para la planeación urbana.

Apoyado en un marco analítico derivado de la teoría institucional y de la teoría de la planeación urbana, este estudio examina los resultados de dos programas de reconstrucción habitacional resultantes de situaciones de crisis en dos de las más complejas megaciudades del mundo: el Programa de Renovación Habitacional Popular (RHP), establecido en la Giudad de México luego del terremoto de 1985; y el Programa Ghost Town (PGT) puesto en marcha en la ciudad de Los Ángeles, California después del terremoto de 1994. Ambos programas han sido reconocidos como exitosos por su acción rápida, fmanciamiento masivo, mejoramiento de las condiciones preexistentes, participación comunitaria y coordinación institucional. Valiéndose de entrevistas, visitas de campo, análisis de datos, y revisión de documentos oficiales y de reportes periodísticos, este estudio intenta dar respuesta a las siguientes interrogantes: ¿En qué sentido las instituciones de planeación urbana en las ciudades de México y Los Ángeles fueron exitosas al manejar las crisis creadas por los sismos? ¿Qué arreglos, políticas, programas y prácticas -convencionales o innovadores- adoptaron estas instituciones al confrontar la turbulencia y el desconcierto creados por los sismos? ¿Cómo respondieron estas instituciones inmersas en contextos políticos y económicos tan distintos a situaciones de crisis similares? ¿Cuáles son las lecciones resultantes de las acciones emprendidas en ambas megaciudades para futuras crisis y para la operación normal de las instituciones de planeación urbana?

La tesis central de este estudio es que las instituciones de planeación logran desempeñarse exitosamente durante situaciones de crisis principalmente porque son capaces de adaptar rutinas institucionales que suelen ser criticadas o rechazadas porque se les considera burocráticas o inflexibles. En los casos de las ciudades de México y Los Ángeles, las instituciones de planeación respondieron efectivamente a la devastación creada por los sismos porque adaptaron rápida y efi- 
cientemente rutinas preexistentes a las nuevas circunstancias. Aunque tales rutinas podrían representar un obstáculo bajo condiciones normales, sirven como herramientas poderosas en circunstancias excepcionales, gracias a su función potencial como conductos a través de los cuales es liberada la energía disciplinada de las instituciones para resolver problemas y restablecer el orden.

Planteado como un estudio de caso, este análisis se propone clarificar y explicar la dinámica de la planeación urbana en un contexto de crisis de dos maneras: Primero, los estudios de caso demuestran que un análisis institucional explícito y sistemático ayuda a entender mejor qué es lo que funciona en materia de planeación urbana, y por qué. Segundo, el análisis institucional muestra bajo qué condiciones pueden servir las rutinas institucionales como herramientas poderosas y efectivas para resolver situaciones imprevistas sin importar el contexto sociopolítico dominante.

Grisis urbana y análisis institucional como un marco teórico

Una situación de crisis es una condición inestable que involucra un cambio abrupto o radical. La noción de que las crisis son un elemento inherente de la vida urbana es cada vez más aceptada, especialmente tratándose de ciudades como Tokio, São Paulo, Nueva York, México y Los Ángeles, que recurrentemente confrontan retos formidables como resultado de crisis naturales y humanas. Para los efectos de este estudio, una crisis es una situación frente a la cual los responsables de la planeación urbana consideran que tal situación existe; esto es, hay un consenso general entre ellos de que la ciudad enfrenta una situación de peligro real, y que la falta de acción en tal circunstancia puede conducir a realidades económicas y políticas sumamente graves (Grindle y Thomas, 1991: 160). Dicho de otra manera, la existencia de una crisis implica la percepción de que la situación presente refleja una disparidad entre lo que es y lo que debe ser.

Bajo una situación de crisis las instituciones públicas y de los grupos en el poder enfrentan una responsabilidad tan alta que la falta de acción puede poner en riesgo su sobrevivencia misma. De esta mane$\mathrm{ra}$, los funcionarios públicos de alto nivel suelen intervenir directamente en la toma de decisiones, buscan la creación de espacios políticos para la introducción de innovaciones y muestran una urgencia extraordinaria por actuar. Cuando la normalidad es la situación do- 
minante estos mismos actores manifiestan un bajo perfil operativo, aunque probablemente hayan sido ellos quienes definieron las líneas de acción que siguen las instituciones. Por lo contrario, en condiciones de normalidad, en la toma de decisiones intervienen principalmente funcionarios de nivel medio y bajo, interesados más en cambios incrementales y con una escasa urgencia por cambios sustantivos (Grindle y Thomas, 1991). Así, las situaciones de crisis pueden ser vistas como un laboratorio extraordinario para observar directamente tres aspectos críticos del funcionamiento de las instituciones de planeación urbana: $a$ ) el destierro y el encumbramiento de políticas urbanas, $b$ ) el espacio político dentro del cual se tomas las decisiones, y o) la reacción de los distintos actores urbanos a cambios abruptos en el ambiente institucional.

De hecho, las crisis son invocadas frecuentemente como justificación para explicar la adopción y adecuación de cambios significativos en las políticas públicas. Desde una perspectiva de clases, por ejemplo, hay quien argumenta que las crisis permiten al Estado ganar mayor autonomía de la sociedad e introducir medidas para incrementar el poder y los privilegios de la clase dominante. Desde una perspectiva racional, una crisis ofrece la oportunidad única de eliminar prácticas ineficientes e introducir en la planeación asuntos estratégicos conectados con el interés colectivo y de largo plazo. Desde un punto de vista político, las crisis pueden ser una fuente de cambio en las reglas del.juego burocrático, ya que contribuyen a definir posiciones y generan oportunidades para competir y renegociar privilegios individuales y colectivos. Desde una perspectiva estatista, una crisis es una oportunidad para que las élites burocráticas definan nuevas estrategias para la resolución de problemas que han afectado el desarrollo de la ciudad en forma crónica, y para tomar un rol activo en la creación de coaliciones que apoyen las reformas que esas mismas burocracias conciben como urgentes. Como puede observarse, un elemento común a todos estos enfoques es que ven en las crisis una opción para transformar la realidad social mediante la introducción de cambios de política significativos (Grindle y Thomas, 1991).

No obstante, desde un punto de vista pragmático la meta institucional más importante de las acciones adoptadas luego de una crisis es el retorno inmediato a la normalidad. La urgencia se explica porque las situaciones de crisis conducen a cambios abruptos que entran en conflicto con la limitada tolerancia humana a cambios rápidos. A una persona común le resulta difícil tolerar que sus creencias básicas sean 
confrontadas o que su vida cotidiana se vea alterada significativamente y de manera prologada. El cambio repentino y continuo produce ansiedad en las personas debido a que pierden el control de la situación y tienen problemas para establecer pautas precisas de comportamiento (Wildavsky, 1979: 224). Así, es comprensible que una crisis que afecta directamente el ambiente construido, dando pie a una situación de caos urbano como el producido por la destrucción masiva de viviendas e infraestructura, genere un nivel de tension y de rechazo a programas de ayuda, albergue temporal y reconstrucción; "particularmente cuando el periodo de emergencia es prolongado y las víctimas son relocalizadas en albergues colectivos por periodos prolongados" (Bolin y Stanford, 1991: 32). En este sentido, un indicador sumario de la efectividad de las instituciones de planeación es su accionar rápido, el financiamiento masivo y el involucramiento de la comunidad en las decisiones críticas para el retorno de la normalidad y la estabilidad en las áreas afectadas. Aún más, la respuesta de las instituciones a una situación de crisis puede conducir no sólo a la normalidad; también a un mejoramiento de las condiciones de vida de los afectados. Así, las crisis pueden ser vistas como una oportunidad para que las instituciones de planeación, y quienes las dirigen, redefinan estrategias para subsanar problemas urbanos estructurales, tomar un rol activo en la creación de una base social para el cambio, y experimentar con programas que no serían viables bajo circunstancias ordinarias.

Esta visión es apoyada por el Comité de Selección del Premio a la Excelencia en Planeación Urbana patrocinado por la Fundación Bruner en la ciudad de Nueva York, que durante los últimos años ha tendido a seleccionar proyectos capaces de sacar ventajas del potencial de transformación que genera una crisis (Schneekloth y Shibley, 1995). Por ejemplo, el suburbio de Quality Hill en Kansas City aprovechó la situación creada por el movimiento de protección del patrimonio urbano y el incendio de un edificio considerado monumento histórico para llamar la atención de los ciudadanos hacia los problemas de escasez de vivienda, deterioro físico y seguridad pública del centro de la ciudad. En otro ejemplo, la ciudad de Boston también aprovechó la crisis que generó el proyecto para crear una vía rápida en el suroeste de la ciudad, para llamar la atención de la opinión pública sobre la urgencia de un programa de preservación urbana, así como para abogar por mejorías al transporte público y el establecimiento de programas de desarrollo económico regional. Otro ejemplo es el proyecto St. Francis Square en San Francisco, que a la vez 
que pretendía detener la crisis provocada por la dispersión urbana y el despoblamiento paulatino de la zona central, también se proponía aminorar la crisis social generada por la escasez de vivienda para la población de bajos recursos.

Sin duda, el grado de efectividad que muestran las instituciones restableciendo la normalidad y la estabilidad, o aun más, mejorando las condiciones de vida de la población urbana después de una crisis, es una prueba clara de su competencia como organizaciones. El reconocimiento de la importancia de las instituciones hace posible su análisis en campos tales como la planeación urbana, con el solo propósito de descubrir qué programas funcionan y por qué. Así, el análisis institucional enfatiza la evaluación de arreglos sistemáticos establecidos-como políticas, planes, programas y prácticas institucionales-, en función de su éxito o fracaso. En este estudio tales arreglos son caracterizados como rutinas institucionales.

Dado que las instituciones establecen reglas y rutinas para gobernar las relaciones entre individuos, son las funciones que desempeñan estas reglas lo que hace a las instituciones relevantes (Lin y $\mathrm{Nu}$ gent, 1995: 2307-2308). Su función básica es economizar, es decir, permitir que uno o más de los agentes gobernados por las reglas de la institución mejoren sus condiciones de bienestar sin menoscabo del bienestar de otros, o permitir que al menos alguno incremente su eficiencia en el marco de sus propias restricciones. Un medio para realizar esta función básica es tomar ventaja de economías de escalas potenciales, de economías de especialización, y/o de economías externas. Otro medio es evitar la realización de errores por parte de individuos y de grupos, por ejemplo, a través de la obtención y análisis de más y mejor información.

El análisis institucional puede ser desagregado en tres niveles dependiendo de qué variables sean tratadas como endógenas (Eggertsson, 1990; Lane, 1993). En el primer nivel el énfasis se pone en los resultados y en la forma en que éstos son determinados por la estructura institucional y las preferencias individuales de quienes los controlan. Así se considera a las instituciones como una variable exógena. En el segundo nivel las instituciones se convierten en el foco del análisis. Su estructura, que en el primer nivel influye en el comportamiento egoísta de individuos y grupos, emerge como el producto de la interacción de éstos en busca de su propio beneficio. En el tercer nivel es preciso explicar el régimen de propiedad, el Estado y las instituciones públicas creadas para el ejercicio de la autoridad y la toma de decisio- 
nes. Aquí se lleva a cabo el estudio de las reglas políticas y económicas; para el examen de las reglas económicas se requiere un modelo del Estado, de la acción de las redes políticas básicas, así como de las estructuras de intereses involucrados. Hemos resumido estos tres niveles de análisis en el cuadro 1.

Las instituciones públicas, foco de este estudio, son una parte importan te del ambiente social, y suelen constituir el marco desde el cual se gobierna una sociedad. Ellas actúan como fuentes de legitimización y poder; proporcionan los medios para la coordinación y distribución de recursos a las diferentes jerarquías de gobierno, y sirven como mecanismos para el establecimiento de reglas y procedimientos aceptados socialmente.

CUADRO 1

Tres niveles de análisis institucional

\begin{tabular}{|c|c|c|}
\hline Enfoque & Elementos de análisis & Fuentes \\
\hline Resultado & $\begin{array}{l}\text { Arreglos institucionales } \\
\text { Estructura institucional } \\
\text { Políticas y reglas } \\
\text { institucionales } \\
\text { Normas y valores } \\
\text { institucionales } \\
\text { Intereses de los actores }\end{array}$ & $\begin{array}{l}\text { Entrevistas con } \\
\text { funcionarios } \\
\text { Observación directa del } \\
\text { comportamiento de las } \\
\text { instituciones } \\
\text { Análisis de documentos } \\
\text { institucionales } \\
\text { Fuentes secundarias }\end{array}$ \\
\hline $\begin{array}{l}\text { Estructura de la } \\
\text { institución }\end{array}$ & $\begin{array}{l}\text { Naturaleza de la interac- } \\
\text { ción entre grupos } \\
\text { Naturaleza de las reglas } \\
\text { legales y políticas }\end{array}$ & $\begin{array}{l}\text { Cuestionarios } \\
\text { Entrevistas con } \\
\text { funcionarios } \\
\text { Análisis de } \\
\text { documentos oficiales } \\
\text { Fuentes secundarias } \\
\text { Estudios de archivos } \\
\text { históricos }\end{array}$ \\
\hline $\begin{array}{l}\text { Sistema } \\
\text { institucional }\end{array}$ & $\begin{array}{l}\text { Relaciones internacionales } \\
\text { Evolución cultural } \\
\text { de la sociedad }\end{array}$ & $\begin{array}{l}\text { Análisis de documentos } \\
\text { oficiales } \\
\text { Fuentes secundarias } \\
\text { Estudio de archivos } \\
\text { históricos }\end{array}$ \\
\hline
\end{tabular}

Fuentes: Elaboración del autor con datos tomados de Eggertson, 1990; Lane, 1993; y Scott, 1995. 
Sin negar la importancia del contexto político y de las motivaciones de los actores individuales, el análisis institucional atribuye un rol más independiente a las instituciones públicas. En algunas discusiones las instituciones del sector público son evaluadas negativamente como organismos aletargados, osificados, y por lo tanto, incapaces de promover el cambio. Esta visión implica que tales organizaciones han adquirido poder y estatus suficiente para actuar con autonomía e independientemente de las necesidades de la población a la que supuestamente deben servir. Sin embargo, si estas organizaciones pierden legitimidad frente a la sociedad, es obvio que declinarán como instituciones. Una institución no puede operar indefinidamente sin producir beneficios (económicos, sociales, políticos y morales) que justifiquen su existencia. En la medida en que dichas organizaciones disfruten de un estatus de legitimidad en la percepción de los ciudadanos, disfrutarán de estabilidad y tendrán mayores posibilidades de sobrevivir que otras organizaciones menos apreciadas y, por lo tanto, menos apoyadas por la sociedad.

En gran parte de la discusión teórica actual sobre el comportamiento de las instituciones se asume que su actuación pública está supeditada a los intereses de las burocracias que las administran. Este supuesto conduce necesariamente a conclusiones pesimistas acerca de su potencial de cambio y de la escasa habilidad de los ciudadanos y de las élites que las manejan para aproximarlas a un concepto más amplio del interés público. Si se juzga a quienes toman decisiones y administran las instituciones públicas como individuos preocupados únicamente en su propio interés, cuyas acciones están motivadas sólo por el deseo de permanecer en el poder (Krueger, 1974; Buchanan, 1980), muy poco puede esperarse de ellos en términos de liderazgo y promoción del cambio. Si toda acción política es asumida como algo que emana del propósito de mantener "cautivo al Estado" para el beneficio personal (Tullock, 1965; Niskanen, 1971), entonces la posibilidad de anticipar un diálogo razonado acerca del contenido de las políticas públicas es realmente limitada.

Claramente, entonces, es necesario un tipo de análisis institucional de las entidades públicas diferente del análisis reduccionista dominado por la idea del interés egoísta, o de las evaluaciones enfocadas solamente a la medición de la eficiencia. Este estudio propone una visión alternativa y más amplia de las instituciones públicas que esté basada en la lógica de cada función y en las acciones orientadas por el proceso. La idea es que quienes analizan los procesos de for- 
mulación y adecuación de políticas públicas, regularmente distinguen características que difícilmente se relacionan con una concepción cuyo resultado derive de la elección de una opción colectiva. Si bien se recolecta la información, se definen las alternativas de política y se realiza el análisis costo-beneficio, todo ello más bien parece encaminado a reconfirmar a los observadores la propiedad de las acciones que están siendo tomadas que a influir en tales acciones (Selznick, 1992). Aún más, los participantes potenciales parecen preocuparse tanto por el privilegio de participar como por el hecho de la participación; recuerdan las características del proceso más fácil y más vividamente que los resultados; sus discusiones acaloradas conducen a decisiones sin reparar en su aplicabilidad; se exige información relevante para las decisiones sin que sea considerada luego; también suele demandarse autoridad que luego no es ejercida (Marzo y Olsen, 1989: 48). Tal concepción de la acción institucional sirve para obtener un entendimien to mejor de la dinámica de las intituciones públicas, especialmente durante las situaciones de crisis en las megaciudades, como habrá de describirse en las siguientes secciones.

\section{Megaciudades en crisis}

\section{Megaciudades}

Las megaciudades son enormes regiones metropolitanas que, de acuerdo con proyecciones de la Organización de las Naciones Unidas, tendrán más de diez millones de habitantes para el año 2000 (Linden, 1993). El crecimiento extremadamente rápido de la población en estos centros urbanos durante el presente siglo ha afectado su infraestructura, su entorno natural, su base económica y sus instituciones; especialmente en aquellos países que ya de por sí enfrentan presiones demográficas y económicas. La monumentalidad de estas megaciudades y de sus problemas hace dudar a algunos de su viabilidad urbanística, especialmente en los casos de aquellas como la Ciudad de México y Los Ángeles que enfrentan fuertes problemas de contaminación atmosférica. En los países industrializados, algunas ciudades están tratando de resolver los problemas creados por la llegada masiva de inmigrantes pobres en un momento en que sus bases fiscales se deterioran por la migración de empresas y de familias de clase media hacia los suburbios, estimuladas principalmente por los altos 
costos de la vida urbana, el crimen y el deterioro de las condiciones de vida.

Las megaciudades son también, sin embargo, un símbolo de lo posible, y esto es verdad tanto en los países industrializados como en los que están en vías de desarrollo. En las ciudades grandes los empresarios conciben sus estrategias y encuentran los mercados y los recursos financieros para hacerlas redituables. Las megaciudades constituyen el espacio donde la tecnología, la industria, y las artes confluyen para crear un ambiente de innovación, y en donde los cambios profundos en la cultura y la política suelen engendrarse casi espontáneamente. Aunque frecuentemente lo olvidemos, megaciudades como la Ciudad de México y Los Ángeles ofrecen también múltiples ejemplos de la efectividad de las instituciones públicas en materia de planeación, como habrán de demostrarlo en este estudio los estudios de caso.

Debido a que muchos aspectos del desarrollo y la vida urbana están ligados al tamaño de la ciudad y a su capacidad institucional, las ciudades de México y Los Ángeles tienen más en común entre sí que con otras ciudades de menor tamaño en sus respectivos países. Ambas concuerdan en el tamaño asombroso de sus poblaciones, y la complejidad que enfrentan las instituciones urbanas encargadas de dar albergue, proveer servicios, y movilizar a millones de personas dentro de los confines de territorios sobredensificados. Otro aspecto común es que la tecnología y la infraestructura en que se sostiene la masiva actividad económica y social de ambas ciudades es muy antigua, y en muchos casos incluye sistemas desarrollados durante el siglo pasado. Asimismo, ambas ciudades tienen que atender una demanda creciente de servicios urbanos con recursos presupuestarios cada vez más limitados, y resolver el problema de la creciente disparidad en los niveles de ingreso que segrega espacialmente a ricos y pobres. La presión sobre las instituciones urbanas en ambas ciudades ha aumentado a medida que una mayor conciencia ambiental ha puesto en la palestra política los problemas de contaminación del aire, el agua, y el suelo, así como su efecto en el deterioro de la calidad de vida.

Por lo que respecta a las estructuras de la población residente en cada ciudad, existen contrastes aunque también similitudes. En la Ciudad de México la mayoría de la población adulta está constituida por migrantes provenientes de otras regiones del país, mientras que en Los Ángeles, aunque una gran proporción de la población adulta también es migrante, su origen es extranjero. Además de la escasez 


\section{CUADRO 2}

\section{Comparación de los perfiles demográfico y habitacional}

\begin{tabular}{|c|c|c|}
\hline Información censal & Ciudad de México & Los Ángeles \\
\hline \multicolumn{3}{|c|}{ Área metropolitana: población y vivienda } \\
\hline Población en el área metropolitana, 1990 & 15.05 millones & 8.86 millones \\
\hline $\begin{array}{l}\text { Tasa de crecimiento de la población } \\
\text { en el área metropolitana, } 1980-1990\end{array}$ & $12.68 \%$ & $18.53 \%$ \\
\hline Viviendas en el área metropolitana, 1990 & 3.12 millones & 3.16 millones \\
\hline \multicolumn{3}{|c|}{ Ciudad central: población y área } \\
\hline Ciudad central: población, 1990 & 8.23 millones & 3.48 millones \\
\hline Ciudad central: área total, 1990 & $1500 \mathrm{~km}^{2}$ & $1215 \mathrm{~km}^{2}$ \\
\hline \multicolumn{3}{|l|}{ Ciudad central: densidad de } \\
\hline la población, 1990 & $5487 \mathrm{hab} . / \mathrm{km}^{2}$ & $2864 \mathrm{hab} . / \mathrm{km}^{2}$ \\
\hline \multicolumn{3}{|c|}{ Ciudad central: viviendas } \\
\hline Ciudad central: número de viviendas, 1990 & 1.80 millones & 1.30 millones \\
\hline Ciudad central: densidad de vivienda, 1990 & $\begin{array}{l}1200 \text { viviendas/ } \\
\mathrm{km}^{2}\end{array}$ & $\begin{array}{l}1070 \text { viviendas/ } \\
\mathrm{km}^{2}\end{array}$ \\
\hline \multicolumn{3}{|l|}{ Viviendas propias ocupadas, y como } \\
\hline porcentajes del total de unidades & $\begin{array}{l}1166385 \text { viviendas } \\
(65 \%)\end{array}$ & $\begin{array}{l}479744 \text { viviendas } \\
(37 \%)\end{array}$ \\
\hline
\end{tabular}
1992.

Fuentes: INEGI, 1992; y U.S. Department of Commerce, Bureau of the Census,

de agua que es común a ambas, las áreas de expansión reciente se caracterizan por sus tasas de ocupación de baja densidad relativa. El problema ha sido lograr el manejo eficiente de la dispersión urbana resultante. Finalmente, aunque en ambas ciudades existen antecedentes de programas gubernamentales para la construcción de vivienda en gran escala, en los años ochenta se efectuaron cambios radicales en las políticas de subsidios. En la Ciudad de México los subsidios sólo fueron otorgados a las víctimas de los sismos de 1985, mientras que en Los Ángeles el enfoque adoptado se inclinó por aplicar políticas por el lado de demanda, por ejemplo, otorgando subsidios a la renta de vivienda. El cuadro 2 presenta un perfil comparativo de la población y de las condiciones de vivienda en las dos ciudades.

Por último, es necesario enfatizar dos importantes diferencias entre las dos ciudades. Primero, muestran importantes diferencias económicas, ya que las tasas de inflación y empleo son relativamente ba- 
jas en Estados Unidos; mientras que en México, la prolongada recesión en la que se sumergió el país después de la devaluación del peso en 1994 ha impedido una mejoría en las condiciones de empleo y de ingreso de la mayoría de la población. Segundo, existen también algunas diferencias físicas y demográficas notables, tales como diferentes tasas de crecimiento poblacional. La tasa de crecimiento de la Ciudad de México ha disminuido en los últimos años, mientras que la ciudad de Los Ángeles continúa siendo una de las regiones metropolitanas de mayor crecimiento en Estados Unidos.

\section{El terremoto de la Ciudad de México}

El primer sismo que en 1985 golpeó a la Ciudad de México ocurrió a las 7:19 a.m. del jueves 19 de septiembre con una intensidad de 8.1 puntos en la escala Richter; el segundo se presentó la tarde siguiente y alcanzó 7.5 puntos en la misma escala. En aproximadamente dos minutos el primer sismo destruyó más de doscientos cincuenta edificios y dañó severamente más de tres mil edificaciones. El reporte oficial de muertos fue de 4287 (Riding, 1986: 5), aunque algunas estimaciones extraoficiales refieren un número de aproximadamente 10000 decesos. Una de las áreas más afectadas fue el centro histórico de la Ciudad de México, y aunque la mayoría de los edificios en la zona permaneció en pie, gran número de monumentos históricos resultaron afectados, lo mismo que hospitales, oficinas federales y hoteles. El gigantesco complejo habitacional de Tlatelolco también fue severamente dañado. En total, alrededor de 100000 unidades habitacionales resultaron afectadas, de las cuales aproximadamente 30000 tuvieron que ser demolidas (Rohter, 1987; Gilbert, 1994). El costo estimado de la reconstrucción y la rehabilitación se calculó en aproximadamente 4000 millones de dólares (de 1985).

Las pérdidas de vidas y la destrucciön física fueron notablemente severas debido a la alta densidad de la población y las edificaciones en el área, así como a la gran concentración de actividad económica. Como es sabido, el subsuelo de la zona central de la Ciudad de México ha sido drenado y rellenado, además de que hasta una profundidad de aproximadamente $\mathbf{4 0}$ metros está compuesto de barro de varias densidades. Una proporción significativa de las estructuras dañadas durante los sismos estaban ubicadas en la zona lacustre. Como resultado de esta localización geológica única -una ciudad asenta- 
da en una superficie de barro altamente poroso- la ciudad reaccionó como gelatina durante el terremoto.

Las unidades habitacionales dañadas por los sismos se concentraban en las delegaciones centrales del Distrito Federal: $60 \%$ en Cuauhtémoc, $34 \%$ en Venustiano Carranza y $6 \%$ en Gustavo A. Madero -donde están las colonias Centro, Morelos, Valle Gómez, Guerrero, Doctores, Obrera y Roma- que en conjunto cubren un área de 4921 hectáreas. Dicha área se caracterizaba por su elevada densidad, el uso mixto del suelo, y una gran cantidad de edificios en malas condiciones. Aquí se hallaba la mayoría de las viviendas de renta controlada de la Ciudad de México, y el nivel de ingreso de los residentes era entre moderado y bajo. La mayoría de las viviendas formaban parte de vecindades, es decir, de estructuras donde un conjunto de viviendas rodea un patio de uso común.

Las estimaciones sobre el número de familias que se quedaron sin casa como resultado de los terremotos varian, aunque el dato oficial final fue de alrededor de 100000 . Las áreas residenciales más afectadas albergaban a un gran número de residentes que desde muchos años antes alquilaban viviendas bajo el régimen de control de rentas, y habían vivido por generaciones en el centro de la ciudad. Decenas de miles quedaron sin vivienda, y muchos más continuaron habitando edificios dañados estructuralmente por los sismos. A dos semanas de la tragedia, la población afectada -de la cual muchos acampaban en calles y plazas- se organizó y movilizó masivamen te para exigir una respuesta del gobierno.

\section{El terremoto de la ciudad de Los Ángeles}

El sismo ocurrió a las 4:31 de la mañana del 17 de enero de 1994 con epicentro en Northridge, un área localizada aproximadamente $\mathbf{2 0 ~ m i - ~}$ llas al noroeste del centro de Los Ángeles. La mejor estimación de la magnitud del terremoto es que tuvo una magnitud de 6.7 puntos en la escala de Ritcher y una duración de veinte segundos (Comerio, 1995: 4). El terremoto de Los Ángeles, también conocido como terremoto de Northridge, dejó 61 muertos, más de 10000 heridos, y 25000 personas sin vivienda. Más de 55000 estructuras resultaron dañadas, de las cuales 1600 quedaron inhabitables (GAO, 1994: 1). El estado de California estimó los daños entre 18000 y 20000 millones de dólares (HUd, 1995: iii). Sin embargo, la magnitud del sismo, el número de víctimas 
humanas, y la escala de la destrucción fueron significativamente inferiores a las observadas en la Ciudad de México en 1985.

La ciudad de Los Ángeles se libró de mayores daños y pérdidas de vidas como resultado de una combinación de buena fortuna y preparación. La fortuna intervino para que la devastación no fuera de mayor magnitud gracias a que el sismo ocurrió en un momento en que las escuelas, los negocios y las calles estaban desiertos porque era un día feriado nacional (día de Martin Luther King). El área también se benefició de la experiencia con que contaba California por haber sufrido otros terremotos, y de la existencia de leyes y programas gubernamentales y privados de preparación que limitaron el daño y permitieron que los sistemas y servicios críticos funcionaran efectivamente durante la emergencia.

La crisis fue particularmente relevante para las instituciones de planeación debido al gran impacto del terremoto en el entorno construido. Por haber afectado directamente un área densamente urbanizada, el terremoto de Northridge ha sido reconocido como el sismo más destructivo en Estados Unidos desde 1906, ya que causó daños significativos en casi todas las áreas de la ciudad y del condado de Los Ángeles. Varios edificios comerciales importantes se colapsaron y cientos de almacenes y oficinas fueron cerrados debido a daños no estructurales, tales como vidrios rotos y techos desplomados. También varios hospitales fueron forzados a evacuar a sus pacientes, y el sistema escolar del condado de Los Ángeles fue puesto en receso para permitir la limpieza y la reparación de los daños. Ocho enormes estacionamientos públicos sufrieron colapsos parciales o totales. Siete puentes fueron severamente dañados o destruidos por el sismo. Las tuberías de agua potable se fracturaron e inundaron las calles; las líneas de conducción de gas también se rompieron y en algunos casos provocaron incendios significativos. El área de Los Ángeles perdió íntegramente el suministro de energía eléctrica.

La crisis no sólo incidió en la infraestructura urbana, sino que también dañó el parque de vivienda de la región. Las estadísticas demuestran claramente que las viviendas, particularmente los edificios de departamentos, sufrieron mayor impacto durante el terremoto: 92\% de todos los edificios inspeccionados fueron residenciales, $y$ $90 \%$ de los edificios evacuados o seriamente dañados fueron unidades multifamiliares (Comerio, 1995: 1). El costo del daño residencial por sî solo fue estimado en más de 1300 millones de dólares (HUD, 1995a: iv). 
Conforme a las estimaciones iniciales, aproximadamente 65252 unidades residenciales registraron daños por 5000 dólares o más, mientras que 19439 unidades fueron condenadas a ser demolidas (LAHD, 1995: 1). En una comparación general, el sismo de Loma Prieta, en las cercanías de San Francisco - un desastre que también afectó principalmente las viviendas multifamiliares en 1989- produjó 43300 unidades dañadas, de las cuales 11600 quedaron completamente destruidas o fueron declaradas inhabitables. El huracán Andrés, que afectó Florida en 1992, dañó 107900 viviendas, principalmente unidades unifamiliares, de las cuales 49000 quedaron completamente destruidas (LAHD, 1995: 4). Aún más, el daño residencial que provocó el sismo de Los Ángeles se concentró casi totalmente dentro de los límites de la ciudad (92\%), de manera similar a lo que ocurrió en la Ciudad de México durante los sismos de 1985.

\section{Respuesta institucional}

\section{Renovación Habitacional Popular}

Después del terremoto de la Ciudad de México, el gobierno federal estableció un programa y una agencia encargada de coordinar la reconstrucción de los barrios y colonias seriamente afectados por los sismos. Debido a que la mayoría de las áreas afectadas se encontraba bajo el régimen de rentas congeladas desde los años cuarenta, los propietarios, que recibían rentas muy bajas, presentaron escasa resistencia a la expropiación de los edificios dañados. Desde el principio los residentes del área participaron activamente en el proceso de planeación. El programa de Renovacion Habitacional Popular (RHP) empezó a construir condominios multifamiliares de tres pisos con el propósito de que las familias damnificadas no salieran de sus barrios. En forma temporal, el RHP proporcionó a los damnificados viviendas provisionales en áreas públicas cercanas, incluyendo calles y banquetas. Finalmente 48749 viviendas fueron construidas, rehabilitadas o reparadas.

El programa RHP se enfocó principalmente a dotar de vivienda a las familias de bajos recursos que resultaron afectadas por el terremoto en la zona central de la Ciudad de México. Dicho programa consumió aproximadamente $55 \%$ del total del presupuesto para reconstrucción autorizado y contribuyó con cerca de $56 \%$ de las unidades 
residenciales creadas después del sismo. Cerca de $80 \%$ de las unidades habitacionales del RHP fueron construcciones nuevas, $12 \%$ fueron unidades rehabilitadas y $1 \%$ unidades con reparaciones menores (RHP, 1988: 110). El desempeño de RHP ha sido considerado exitoso en varios sentidos, incluyendo su acción rápida, financiamiento masivo, participación comunitaria, mejoría de las condiciones preexistentes y coordinación institucional.

\section{Programa Ghost Town}

El Concejo de la ciudad de Los Ángeles, el alcalde, y más notoriamente el Departamento de Vivienda de Los Ángeles (LAHD, por sus siglas en inglés), previeron que los barrios que habían sufrido mayores daños residenciales afectarían permanentemente a la ciudad a menos que se tomaran acciones para asegurar su estabilización y reconstrucción inmediata. Una de las iniciativas más importantes para reconstruir las áreas más dañadas fue una moción que presentó el Comité Especial del Concejo de la Ciudad para la Recuperación del Sismo el 20 de mayo de 1994, indicando la necesidad de "crear una fuerza de tarea que atendiera los problemas de vandalismo en los edificios dañados por el sismo y que informara al Comité Especial en el curso de dos semanas" (Alarcón, 1994).

La definición oficial de "área afectada" fue establecida posteriormente como un "área que concentrara 100 o más unidades habitacionales que hubieran experimentado daños con un valor de 5000 dólares o más por unidad" (LAHD, 1994: 2) y el término ghost town fue adoptado para referirse a ellas. El gobierno de la ciudad de Los Ángeles y sus instituciones de vivienda actuaron con rapidez para limpiar, controlar y restablecer estos barrios y su área circunvecina. LAHD fue designado organismo líder para estabilizar los ghost towns. Antes del sismo de Los Ángeles los principales programas federales de asistencia en caso de desastres eran manejados por la Administración de Pequeños Negocios (SBA, por sus siglas en inglés) y por la Agencia Federal para el Manejo de Emergencias (FEMA, por sus siglas en inglés). Estos programas fueron diseñados principalmente para ayudar a los propietarios de viviendas unifamiliares y por lo mismo no estaban preparados para atender la emergencia creada por un sismo en el que $92 \%$ de las viviendas dañadas fueron unidades multifamiliares. Con el objeto de llenar el vacío institucional existente, LAHD fue res- 
tructurado para atender la crisis en forma prioritaria mediante la reasignación de personal, la reorientación de sus programas, y el diseño y financiamiento de nuevos programas (LAHD, 1996).

El producto de esta reestructuración fue el Programa Ghost Towns (PGT) que, como en el caso de la Ciudad de México, logró resultados exitosos, incluyendo la acción rápida, el financiamiento masivo, la participación pública y la coordinación institucional. También como en el caso de la Ciudad de México, los resultados se basaron en rutinas institucionales, es decir, en políticas, programas y prácticas propios de las instituciones particulares. Los resultados exitosos de RHP y PGT, así como las rutinas institucionales en las que se basaron, serán discutidos en las siguientes secciones.

\section{Resultados exitosos}

\section{Acción rápida}

El resultado más significativo de los esfuerzos de los programas de vivienda fue una serie de logros derivados de decisiones rápidas. En Los Ángeles el Departamento de Vivienda y Desarrollo Urbano de Estados Unidos (HUD, por sus siglas en inglés) y los organismos locales de vivienda recibieron evaluaciones muy positivas por su reacción expedita. "Ellos han actuado increíblemente rápido. HUD ha reaccionado de una manera que no se había visto en muchos años...", dijo Jan Breidenbach (citado por Stanfield, 1994: 392), directora ejecutiva de la Asociación de Vivienda de Interés Social del Sur de California, una organización de Los Ángeles que construye vivienda subsidiada.

El 28 de junio de 1994 el Concejo de la Ciudad de Los Ángeles aprobó los primeros créditos para construcción mediante los programas de emergencia de LAHD, por un total de 7.5 millones de dólares (LAHD, 1994: 2-4). Días despues, el 23 de julio, LAHD y sus instituciones afiliadas pusieron en marcha un plan multietápico para la recuperación de los 13 ghost towns identificados hasta el momento en el Valle de San Fernando, Hollywood y Mid-City. La ciudad contrató guardias privados para mantener a algunos grupos de vándalos alejados de los edificios dañados en esas áreas (Martin, 1994: B3). El 27 de julio el alcalde Richard Riordan solicitó al presidente Clinton la canalización de fondos no ejercidos por la FEMA para asistir a los propietarios de condominios y departamentos en áreas afectadas por el sismo. 
El presidente Clinton estuvo de acuerdo en buscar a partir de agosto la transferencia de $\mathbf{2 2 5}$ millones de fondos originalmente destinados a la construccción de carreteras y escuelas, medida que fue aprobada por el Congreso (Smith, 1994: B3-B5). Con estos fondos, las ciudades de Los Ángeles y Santa Mónica fueron capaces de otorgar créditos sin interés por 30 años a los propietarios de los edificios dañados (HUD, 1995a: 8).

La celeridad de la acción institucional se mantuvo constante. En diciembre de 1994 había un total de 1030 edificios de departamentos en los ghost towns, y de éstos, 29 fueron demolidos y 301 quedaron vacantes. A dos años del terremoto, LAHD, SBA y algunas agencias privadas habían financiado $99 \%$ de los 7506 departamentos abandonados, de los cuales $84 \%$ estaba en proceso de recontrucción o había sido reconstruido (LAHD, 1996). Para mayo de 1996 había solamente 83 edificios abandonados. De los 301 que fueron abandonados originalmente, 269 edificios con 6473 departamentos estaban en proceso de reconstrucción o ya totalmente reconstruidos. Un total de 7503 departamentos tenían fondos comprometidos para su rehabilitación. Esta cantidad representaba más de $99 \%$ de los departamentos abandonados después del sismo. Obras de reconstrucción se hallaban en proceso en 53 edificios con 1408 departamentos, es decir, $19 \%$ de los departamentos desalojados. Las obras de reconstrucción habían sido concluidas en 5065 departamentos o $65 \%$ de las unidades afectadas (Earthquake Ghost Town Task Force, 1996: 2).

De la misma manera, el gobierno mexicano respondió a la aguda crisis con la agilidad de una maquinaria política experimentada y urgida de restablecer a la brevedad posible su legitimidad y autoridad: "El mayor éxito fue la rapidez con que fue organizado el RHP" (Eibenschutz, 1995). Respondiendo a crecientes protestas, una semana después del sismo el gobierno empezó a construir aproximadamente 22000 viviendas provisionales cerca de los sitios donde se hallaban las vecindades destruidas. El gobierno también ofreció un subsidio de alquiler a aquellas familias que optaron por reubicarse con familiares y amigos. Apenas una semana después del sismo, el presidente Miguel de la Madrid también ordenó la revisión del código de construcción de la Ciudad de México. Otro plan de acción fue revelado el 27 de septiembre -sólo 8 días después del terremoto- en una reunión de funcionarios con residentes de la delegación Benito Juárez. Los funcionarios ofrecieron a los residentes desplazados ayuda para comprar casas en la periferia de la ciudad, pero enfrentaron una fuerte resistencia de parte de aquéllos, 
que enfurecidos demandaban que el gobierno reconstruyera las viviendas en sus sitios originales, aun cuando esto significara habitar durante varios meses en albergues provisionales. Al final, esto se convirtió en la base para el programa RHP. La acción rápida que fue característica del RHP es poco común entre los programas de vivienda mexicanos.

El paso inicial y más crítico para hacer la reconstrucción de vivienda no sólo posible sino también exitosa fue la expropiación de los edificios más severamente dañados por el sismo. El decreto fue expedido originalmente el 11 de octubre de 1985, menos de un mes después del terremoto, y sirvió para expropiar 5500 predios. El RHP y la agencia que operaba el programa fueron creados tres días después, el 14 de octubre. El primer decreto fue expedido en medio de mucha presión social y política para que el gobierno respondiera a las necesidades de los damnificados, lo que resultó en un documento apresurado que contenía varios problemas técnicos. De esta manera, un segundo decreto fue expedido el 22 de octubre de 1985 y con él se expropió un total de 3121 propiedades. Tal decreto, aunque drástico, fue considerado un acierto político. Primero, identificó rápidamente al grupo de beneficiarios del programa de reconstrucción de vivienda. Segundo, puso a disposición del RHP los terrenos para la reconstrucción, que eran el insumo más crítico para el éxito del programa. Tercero, muchos de los propietarios estaban satisfechos al lograr deshacerse de edificios que no les generaban suficientes ingresos debido al control de rentas.

La rapidez de la acción institucional tanto en Los Ángeles como en la Ciudad de México se apoyó principalmente en estructuras institucionales preexistentes, incluyendo las relaciones entre las oficinas de planeación local, organismos federales e instituciones financieras. Por ejemplo, la acción rápida del RHP fue resultado principalmente de arreglos entre el gobierno de la Ciudad de México, la Secretaría de Desarollo Urbano y Ecología (Sedue), el Banco Nacional de Obras Públicas, y el Fondo Nacional para la Habitación Popular (Fonhapo) en el ámbito federal, y el Banco Mundial en el internacional. Similarmente, la acción rápida en Los Ángeles estuvo basada en relaciones preexistentes entre el Concejo de la Ciudad de Los Ángeles y el LAHD con carácter local, y la SBA y HUD en el ámbito federal. 


\section{Financiamiento masivo}

Un segundo resultado exitoso, el financiamiento masivo, fue la respuesta a las enormes necesidades financieras creadas por la extensa destrucción que ocasionaron los terremotos en la Ciudad de México y en Los Ángeles. Dadas las terribles circunstancias creadas por el sismo en Los Ángeles, el monto de la asistencia federal estableció un récord, ya que el gobierno solicitó 11.2 billones de dólares en ayuda, más de lo que se había pedido para cualquier desastre previo en Estados Unidos. Después de consultar con las autoridades locales, el 1 de abril de 1994 HUD desembolsó 30 millones provenientes de su fondo para contingencias locales, posibilitando que las organizaciones de vivienda emprendieran un esfuerzo masivo para reconstruir los barrios afectados. Posteriormente, una vez que el Congreso autorizó un presupuesto suplementario, HUD proporcionó un monto adicional de 225 millones para reforzar los programas de reconstrucción (Galster et al., 1995). Los recursos obtenidos de partidas federales no ejercidas para la reparación de carreteras federales y de escuelas, sirvieron para otorgar créditos sin intereses, y de esta manera subsidiar a los propietarios afectados.

FEMA y la oficina de servicios de emergencia del estado de California gastaron 6.5 millones en donativos de emergencia para los propietarios de edificios dañados. Cerca de 200 millones en financiamiento adicional llegó a las zonas afectadas por medio de aseguradoras privadas, créditos federales de la SBA, o créditos de bancos privados (Martin, 1995: 20). En adición, poco después de que la ciudad había reconocido la gravedad de la situación en los ghost towns, la SBA decidió revisar 28000 solicitudes de créditos de emergencia que fueron rechazados o negados, y darle prioridad a las solicitudes presentadas por los propietarios de los ghost towns.

La ciudad de Los Ángeles proporcionó créditos sin intereses o de bajo interés hasta por 50 mil dólares a propietarios de unidades unifamiliares, utilizando un fondo creado con capital del gobierno federal y recursos locales destinados a la construcción de vivienda. Además, mediante la reorganización de personal para acelerar el procesamiento de los créditos, LAHD desarrolló una unidad de financiamiento especializada en los ghost towns que administró 22.5 millones en fondos suplementarios otorgados por HUD, en adición a otros fondos disponibles (LAHD, 1995: 10-11). El otorgamiento de créditos se apoyó en procedimientos que existían antes de la situación de crisis, y 
que son comunes en la mayoría de las instituciones locales de vivienda. Así, el personal encargado de procesar los créditos estaba familiarizado con ellos. Asimismo, LAHD tenía también una experiencia bien establecida en el procesamiento de créditos para vivienda del tipo utilizado por el programa ghost town. Por ejemplo, en 1991 LAHD, entonces conocido como el Departamento de Producción y Preservación de Vivienda, proporcionó créditos a 477 propietarios de residencias unifamiliares y edificios de departamentos para la rehabilitación de 2 256 unidades habitacionales. Esto representó una inversión pública y privada de 24 millones (Squier, 1992:1).

En la Ciudad de México, un componente crucial para el éxito del RHP fue la disponibilidad de recursos financieros listos para ser aplicados. Cuando el RHP estaba en plena operación, administraba semanalmente un promedio de 13 millones de dólares. El programa recibió un total de 172 millones de dólares entre 1986 y 1987 como parte del presupuesto nacional (Ebrard y Gamboa del Buen, 1991: 25). Fueron utilizados dos tipos de fondos: $a$ ) fondos especiales para la recuperación de vivienda asignados por el gobierno mexicano; y $b$ ) un préstamo del Banco Mundial. Los recursos financieros de RHP sumaron 274624.5 millones de pesos en total, o aproximadamente $392 \mathrm{mi}$ llones de dólares de 1985 , de los cuales cerca de $55 \%$ provino del gobierno mexicano y el resto del Banco Mundial (Perló, 1991: 16).

Los fondos del Banco Mundial fueron utilizados para el pago de los costos directos de construcción, mientras que los recursos federales fueron asignados para el financiamiento de gastos indirectos, como diseños y estudios arquitectónicos, supervisión de obra, alojamien to temporal, subsidios para alquiler de vivienda, y costos de operación del RHP. El primero de los préstamos del Banco Mundial, por un total de 164 millones de dólares, había sido negociado en 1981 para el desarrollo urbano de la región del Istmo de Tehuantepec. Como no habían sido usados al momento del terremoto, la mitad de los fondos fueron transferidos al programa de reconstrucción de vivienda en la Ciudad de México. Posteriormente fueron negociados recursos adicionales para este programa y su seguimiento, y los préstamos del Banco Mundial se integraron a los fondos canalizados a Banobras por medio de Fonhapo (Connolly, 1990: 27).

Aunque el monto de recursos proveniente del Banco Mundial no tenía precedente, su administración se basó en un número de rutinas institucionales preexistentes. Por ejemplo, una parte del dinero fue canalizado mediante proyectos de infraestructura preaprobados por 
Banobras. Aún más, al momento de sobrevenir el terremoto Fonhapo estaba en medio de una negociación con el Banco Mundial para financiar vivienda, y los criterios y mecanismos para el financiamiento del RHP estuvieron basados en las discusiones sostenidas durante esas negociaciones (Gamboa, 1995). Así, mientras el RHP era encomiado como una agencia eficiente e independiente, estaba recibiendo financiamiento valiéndose de los mecanismos establecidos por Banobras y Fonhapo, dos instituciones de desarrollo de viviendas e infraestructura que habían tenido éxito en la adecuación de sus propios programas.

\section{Mejoria de las condiciones}

Un tercer resultado exitoso es la mejoría de las condiciones de las áreas afectadas, tal y como se reflejó en tres indicadores: seguridad, estabilidad y mejoría física de los barrios devastados.

En Los Ángeles la condición de los 17 ghost town abandonados era desastrosa: en los barrios deshabitados, las ratas y las cucarachas proliferaron. Las albercas estancadas y abandonadas se convirtieron en criaderos de mosquitos y las autoridades sanitarias ordenaron que fueran drenadas. En el ghost town de Sylmar, los vándalos destruían las ventanas y puertas de vidrio, y lanzaban el mobiliario de las casas a través de la ventana (Mydans, 1994: 12). Así, razones económicas y sociales volvieron impostergable restablecer las condiciones fisicas de esos barrios a su estado anterior. Sin embargo el programa ghost toum logró más que eso, ya que ayudó a revitalizar el área de tal manera que se advierte una mejoría si se compara con las condiciones previas al sismo.

La tarea inmediata para el mejoramiento de las condiciones fue garantizar la seguridad de los residentes que decidieron permanecer allí, y de las casas y departamentos abandonados por sus ocupantes. El Departamento de Policía de Los Ángeles se encargó de realizar redadas en los barrios afectados por el sismo para limpiar las propiedades abandonadas de invasores y vándalos. Simultáneamente, el Departamento de Obras Públicas cercó las propiedades cuando no lo habían hecho sus propietarios. En consulta con el Departamento de Policía, el Departamento de Obras Públicas fijó letreros de "no traspasar", y se solicitó a los propietarios que autorizaran al Departamento de Policía el arresto de invasores (Earthquake Ghost Town Task Force, 1994: 2). 
Una segunda acción para mejorar las condiciones de las áreas afectadas fue promover la estabilización física y psicológica de los barrios devastados. El objetivo del Programa Ghost Town fue revitalizar cada barrio afectado in situ, tanto en términos de la comunidad como del lugar físico, en vez de reubicar a los residentes en otras área de la ciudad. Esta estrategia fue importante considerando el apego de la gente a sus comunidades, a sus trabajos, sus iglesias, sus escuelas, sus amigos, sus tintorerías y supermercados. Generalmente las víctimas de un desastre se ven forzadas a enfrentar situaciones nuevas y dificiles, por lo que su deseo de retornar al patrón social previo ordinariamente es muy alto (Bolin y Stanford, 1991).

La tercera acción fue el mejoramiento de las condiciones fisicas de la vivienda. En muchas áreas la calidad de la vivienda superó notablemente las condiciones presismo debido a que se sujetó a normas de construcción y diseño más estrictas, y a otras exigencias que acompañaron los créditos subsidiados. Rutinas institucionales -tales como las regulaciones de HUD- sirvieron para promover el mejoramiento de todas las unidades aseguradas con fondos federales al exigir que sus estructuras cumplieran con los estándares mínimos establecidos por el Departamento que, en general, son más estrictos que los códigos de construcción de la ciudad de Los Ángeles.

Por lo que toca al RHP, una parte de su éxito al promover la mejoría en las condiciones de las áreas afectadas derivó de la estrategia de dotar a sus residentes con viviendas construidas en los mismos barrios que habitaban con anterioridad. A pesar de la importancia de las políticas de descentralización, el gobierno optó por la solución políticamente aceptable de ayudar a la población afectada in situ. Esta estrategia también garantizó, quizá inadvertidamente, que muchas familias de bajos ingresos que vivían cerca de sus centros de trabajo en la Ciudad de México y que no tenían posibilidades de costear elevados gastos de transporte, no fueran afectadas por una reubicación forzada. De hecho, la mayoría de las familias había vivido en el área por más de 30 años y consecuentemente estaban plenamente integradas a sus comunidades. Casi $40 \%$ vivía y trabajaba en la misma zona (RHP, 1988).

Otro aspecto que contribuyó a la mejoría de las condiciones fue el cambio de una tenencia incierta y problemática a un estatus de propiedad más seguro que podía ser considerado como una inversión patrimonial. Antes del sismo, la gran mayoría de las familias afectadas $-97 \%$ de los entrevistados en un estudio del RHP (RHP, 1988)-rentaban el lugar donde vivían. Después del sismo muchos de los antiguos 
arrendatarios se convirtieron en copropietarios de una unidad habitacional renovada.

Un tercer aspecto comprendió el tamaño, los servicios, y el diseno físico de las nuevas viviendas. Las condiciones físicas en las que vivía la mayoría de las familias afectadas se encontraban entre las peores de la Ciudad de México (Perló, 1991). Antes del sismo, el tamaño promedio de las viviendas era de un poco más de 18 metros cuadrados (RHP, 1988); en cuanto a su estado físico, alrededor de $25 \%$ se encontraba en malas condiciones, mostrando fuerte deterioro; alrededor de $62 \%$ era considerado regular, y solamente $9 \%$ estaba en buenas condiciones. Después de los sismos $18 \%$ quedó inhabitable. Cada nuevo apartamento construido por el RHP, por otro lado, tenía 40 metros cuadrados de espacio habitable, incluía un baño, un sanitario, área para lavar y cocineta. Así, en la mayoría de los casos, las familias dispusieron de más espacio del que tenían antes del terremoto. "Esto está mucho más bonito -opinó Petra Hernández, de 68 años de edad, quien vivió en una vecindad por más de 40 años- antes teníamos un cuarto y un excusado, ahora tenemos dos recámaras, un excusado, y una regadera" (citado por Stockton, 1986: 13).

\section{Participación comunitaria}

Un cuarto resultado exitoso, la participación comunitaria, se reflejó en las diversas iniciativas de participación comunitaria dirigidas específicamente a los barrios afectados.

LAHD se puso en contacto con los propietarios para ofrecerles ayuda, participó en reuniones comunitarias y colaboró con una institución no lucrativa -Habitat para la Humanidad-para reconstruir un ghost town de bajos ingresos. Estos esfuerzos fueron el resultado de rutinas utilizadas por LAHD para tratar con las comunidades a las que sirve regularmente.

LAHD creó una línea telefónica especial para atender todas las necesidades de vivienda y de información relacionadas con el sismo, incluyendo los ghost town, mediante la ampliación de las funciones de la línea de información para la estabilización de rentas. Durante el primer año de operación, un total de 162000 llamadas fueron recibidas por la Sección de Información Pública de LAHD (LAHD, 1995: 8). Otras actividades de participación comunitaria de LAHD incluyeron la colaboración con los Centros Comunitarios para la Asistencia de las 
Víctimas del Desastre, los Grupos de Apoyo, y la participación en un Foro para la Recuperación del Sismo, que fue realizado en el Centro de Convenciones de Los Ángeles con el propósito de ayudar a los propietarios de unidades multifamiliares a resolver obstáculos financieros, llenar vacantes y obtener asistencia individual de SBA, de LAHD y de instituciones financieras privadas. La reunión fue copatrocinada por LAHD, la Asociación de Propietarios de Departamentos del Área Metropolitana de Los Ángeles, y HUD. LAHD también participó en otras actividades patrocinadas por varias instituciones caritativas y gubernamentales durante los tres meses posteriores al sismo.

Las bases para estos esfuerzos de participación comunitaria pueden encontrarse en una variedad de rutinas institucionales preexistentes. En 1991 LAHD estuvo involucrado en una variedad de proyectos comunitarios que incluían alianzas con organizaciones comunitarias no lucrativas. Un ejemplo fue el financiamiento de una institución llamada Concern Citizens of South Central Los Ángeles, que proponía la construcción de un edificio de 18 departamentos y una imprenta para proporcionar capacitación a residentes del área. Un segundo ejemplo es un proyecto para otorgar créditos a otra institucion con el afán de adquirir y rehabilitar un edificio abandonado, dar en él residencia a 24 enfermos mentales y brindarles servicios médicos y psicológicos en el sitio (Squier, 1992: 2).

En México, por otra parte, la participación de la comunidad fue canalizada por el gobierno mediante el Convenio de Concertación Democrática para la Reconstrucción de Vivienda. Este convenio fue un elemento clave para la instauración del RHP, dado que fue resultado de negociaciones políticas dificiles y prolongadas, y sirvió como un pacto político y social. El rol de liderazgo de las instituciones de planeación del sector público, así como su legitimidad y aparente equidad, fueron reconocidos por las organizaciones políticas y sociales más importantes de la Ciudad de México.

Algunos sectores sociales, particularmente aquellos más afectados por la crisis fiscal en la Ciudad de México en los años setenta y ochenta, desarrollaron nuevas organizaciones y un importante movimiento urbano durante ese periodo. Los pobres de la ciudad y el sector popular, preocupados por la reducción de los niveles de vida y las pocas oportunidades de participación política, empezaron a formar grupos fuera de los canales gubernamentales (v.g., concejos de barrio) y a confrontar el marco institucional existente. Entre las organizaciones más independientes se encontraban el Frente Popular Independiente del Valle de México, 
que después se transformó en el Frente Popular Netzahualcóyotl; la Unión de Vecinos de la Colonia Guerrero; y la Coordinadora Nacional Provisional del Movimiento Popular, que fue posteriormente transformada en el Consejo Nacional de Movimientos Urbanos Populares (Gonamup) (Campbell y Wilk, 1986). Así, las clases populares de la Ciudad de México ya habían establecido canales para plantear sus demandas y ser escuchadas, para construir consensos, o para modificar las prioridades de la acción gubernamental, como fue el caso del programa RHP.

\section{Coordinación institucional}

Un quinto resultado encomiable fue la coordinación institucional. El programa Ghost Town fue exitoso porque logró operar efectivamente mecanismos de coordinación tales como el Grupo de Trabajo Ad Hoc de la ciudad de Los Ángeles; incluyó esfuerzos de colaboración entre diferentes instituciones, tales como la base de datos de SBA y LAHD; y coordinó recursos financieros de instituciones federales, estatales y locales, así como del sector privado y público.

Seis meses después del sismo, la ciudad de Los Ángeles estableció un Grupo de Trabajo Ad Hoc para gestionar acuerdos especiales entre instituciones de crédito y propietarios en las áreas afectadas, con el objeto de ayudar a aquellos dueños con problemas financieros a conseguir un receso en el pago de sus hipotecas durante el periodo de reconstrucción. Un memorándum de este grupo de trabajo identificó al menos a 11 diferentes instituciones que intervinieron en los esfuerzos de reconstrucción, incluyendo al Concejo de la Ciudad, la Oficina del Alcalde, LAHD, el Departamento de Inspección de Los Ángeles, el Departamento de Obras Públicas, el Departamento de Policía, el Departamento de Servicios Generales, la Oficina de Servicios de Emergencia del Estado de California, FEMA, HUD y SBA.

No es difícil encontrar en Los Ángeles antecedentes de casos de coordinación institucional, especialmente en términos de integración horizontal después de situaciones de crisis. La coordinación vertical suele ser asegurada por las rutinas federales de manejo de crisis. De hecho, la participación federal en programas de estabilización y reconstrucción en caso de desastres es manejada por FEMA desde su establecimiento en 1974.

De manera similar, en la Ciudad de México fue concluida la enorme y compleja tarea de construir, reparar o rehabilitar 48749 vivien- 
das en aproximadamente dos años, con la participación de 1244 organismos del sector privado, incluyendo 738 compañías constructoras, 64 empresas con contratos de supervisión, 184 provedores, y 258 pequeñas y medianas empresas encargadas del diseño arquitectónico y la construcción (Ebrard y Gamboa, 1991: 22; RHP, 1988: 10).

Con el propósito de conectar diversos programas de reconstrucción, incluyendo el RHP mismo, en diciembre de 1985 se estableció un grupo de coordinación técnica interinstitucional. El grupo operó bajo la autoridad de la Secretaría de Programación y Presupuesto, y estuvo integrado por expertos en economía, derecho, planeación urbana, vivienda, salud pública, comunicación, descentralización, programación y finanzas. La operación y eficiencia de los programas de recuperación fue responsabilidad del titular de cada sector, incluyendo desarrollo urbano y vivienda, comunicaciones y transporte, comercio e industria, salud y educación, así como al Instituto Mexicano del Seguro Social y al Departamento del Distrito Federal (DDF). Tal coordinación institucional, que fue realmente efectiva, debió su éxito no tanto a la creación de nuevos organismos o a la adopción de estrategias innovadoras, sino a la aplicación de rutinas preexistentes.

Fueron creados mecanismos de coordinación institucional, tales como los Comités de Consulta Técnica, para vigilar e inspeccionar los estándares de construcción en proyectos no gubernamentales financiados por el RHP. El decreto inicial de expropiación fue instrumentado por el DDF, mientras que los programas de renovación habitacional fueron manejados por el gobierno federal. Aún más, el acuerdo y la coordinación de más de un centenar de instituciones en los sectores público, privado y no lucrativo fueron en realidad un gran reto. Estos ejemplos de coordinación institucional fueron en realidad facilitados por la preexistencia de relaciones institucionales que dependían principalmente de la estructura institucional vertical y altamente centralizada que caracteriza el sector público mexicano, y que frecuentemente es manejada desde Los Pinos. También, aunque la fuerte participación del Banco Mundial en programas de renovación habitacional como el RHP parece no tener precedente, ésta fue realmente una modificación de proyectos, préstamos, y negociaciones en curso para programas ordinarios de desarrollo de vivienda (Gamboa de Buen, 1995; Stolarski, 1995). 
Importancia de las rutinas institucionales

\section{Relevancia de las rutinas}

El estudio de los programas de reconstrucción de vivienda después de los sismos en la Ciudad de México y en Los Ángeles indican claramente la importancia de las rutinas para las instituciones de planeación. Un repertorio de rutinas - tales como convenios, programas, y prácticas institucionales bien establecidas y probadas-, no es sólo útil para manejar situaciones repetitivas y simples, sino que también puede ser la base para la acción institucional frente a situaciones imprevistas, incluyendo las crisis urbanas. En última instancia, la cualidad de ser nuevo no es algo inherente a una situación particular, por lo menos no tanto como lo es de nuestra propia reacción ante dicha situación; y la respuesta institucional más común frente a la novedad es encontrar el conjunto de rutinas que se adecuen mejor a dicha situación. De hecho, los problemas no tienen una estructura intrínseca, sino que adquieren una estructura por referencia a las soluciones que los individuos y las instituciones pueden imaginar, lo que en última instancia depende de nuestro deseo de resolver problemas de una manera consistente con nuestro entendimiento. Aún más, al manejar el cambio para hacerlo más consistente con los procedimientos y prácticas existentes, las instituciones mantienen su estabilidad frente a las presiones que este mismo ejerce.

La ubicuidad de las rutinas frecuentemente hace que las instituciones públicas aparezcan como estructuras burocráticas, rígidas e insensibles, muchas veces con justificación. La simplificación que proporcionan las rutinas está lejos de ser perfecta, al referirse a una realidad que regularmente enfrentamos post facto. Sin embargo, una de las principales habilidades de las intituciones modernas de planeación proviene de su efectividad para sustituir conductas rutinarias por conductas individualmente autónomas. Las rutinas hacen posible la coordinación simultánea de múltiples actividades y vuelven los objetivos de estas acciones mutuamente consistentes. Las rutinas ayudan a evitar conflictos, proporcionan códigos de entendimiento que facilitan la interpretación de mundos ambiguos, delimitan el ámbito de negociación y facilitan acuerdos, y ayudan a mitigar situaciones impredecibles mediante el confinamiento de los participantes a un número delimitado de problemas y soluciones (March y Olsen, 1989). 
La importancia de las rutinas durante una crisis se deriva del hecho de que la continuidad -o lo que las personas hacían antes de la crisis- es el mejor predictor de su comportamiento cuando la crisis estalla. La literatura sobre desastres (Neal y Philip, 1995) indica que el comportamiento colectivo depende de factores como la experiencia previa con desastres, las características de la comunidad y la influencia de las redes sociales. En esencia, estudios y datos previos muestran que las relaciones sociales e institucionales preexistentes facilitan las labores de emergencia y son una fuente de soluciones innovadoras para auxiliar de manera efectiva a las víctimas de un desastre.

En realidad, la puesta en marcha de los programas RHP y PGT se basó, similarmente y en el mismo grado, en convenios, políticas, programas y prácticas existentes. Las entrevistas en la Ciudad de México y en Los Angeles revelaron que la mayoría de los funcionarios públicos que participaron en los programas de reconstrucción de vivienda trabajaban en instituciones preexistentes, tenían una experiencia considerable en el financiamiento y desarrollo de programas habitacionales, y se apoyaron en estos recursos para formular propuestas, más que para pensar en nuevas ideas. El uso de viejas estrategias para enfrentar la novedad producida por una situación de crisis puede ser efectiva por una variedad de razones, incluyendo la legitimidad, la especialización y la aptitud de las instituciones.

\section{Legitimidad institucional}

Frecuentemente los estudios sobre las instituciones públicas de planeación (Johnson, 1989; Self, 1982), tales como las que participaron en los programas de reconstrucción en la Ciudad de México y en Los Ángeles, explican que el surgimiento de políticas es resultado del oportunismo político, de la búsqueda de equidad social o de eficiencia económica. Sin embargo, la evidencia indica la presencia de otro factor crítico: la necesidad que tienen las instituciones de dar legitimidad a sus acciones. Las instituciones públicas surgen sólo si pueden establecer su legitimidad, y perviven sólo si son capaces de mantener esa legitimidad al cumplir con propósitos socialmente aceptados. En un aspecto estrictamente instrumental, las instituciones de planeación y los individuos que las integran necesitan comunicarle a la opinión pública que sus acciones son legítimas. La legitimidad se gana demostrando que las acciones que se realizan 
satisfacen objetivos apropiados y que, además, se ejecutan de manera adecuada.

En la Ciudad de México, tanto en términos económicos (en respuesta a la severa recesión) como sociales (para reducir las protestas de los damnificados), el RHP sirvió como un instrumento para fortalecer la legitimidad del gobierno, lo mismo que como un mecanismo para resolver las necesidades inmediatas de vivienda. Una manera en que las instituciones públicas lograron obtener cierta legitimidad para:justificar sus acciones en la Ciudad de México fue por medio del Convenio de Concertación Democrática para la Reconstrucción de Vivienda. Este acuerdo fue firmado ocho meses después del terremoto por 106 instituciones públicas, universidades, grupos de apoyo técnico, asociaciones de profesionistas y organismos internacionales. Si se considera el carácter altamente centralizado y jerárquico de la estructura institucional de México, es comprensible que el apoyo de la Presidencia haya sido crítico. El presidente Miguel de la Madrid estuvo en las calles al menos una docena de veces -al igual que el presidente Clinton y algunos miembros de su gabinete en Los Ángeles en 1994- visitando las áreas más afectadas por los sismos para alentar a sus residentes y prometerles ayuda. La naturaleza simbólica y el carácter político de tales gestos fueron enfatizados por las instituciones públicas. Por ejemplo, en una transmisión televisiva pagada por el gobierno mexicano, el comentarista dijo: “ ¿No es impresionante cómo nuestro presidente convive con los afectados? ¿No somos afortunados al tener un líder así? Es evidente el alivio que producen en la gente sus visitas" (citado en Meislin, 1985: 3).

\section{Especialización institucional}

Las rutinas también reflejan la especialización de las instituciones. Las encargadas de la planeación crean un conjunto de programas y políticas en áreas como vivienda o transporte, para atender una diversidad de problemas. Este repertorio de programas y políticas especializadas sintetiza el conocimiento y la pericia de las instituciones y forma una plataforma de competencias básicas que pueden ser adaptadas a situaciones ambiguas, aun a aquellas que no están directamente definidas dentro del universo de propósitos y capacidades institucionales. La especialización mediante un inventario de rutinas constituye una salvaguarda en contra de contingencias, y frecuentemente parece du- 
plicar prácticas dentro de las instituciones urbanas. No obstante su connotación negativa, algunos analistas (Caiden y Wildavsky, 1974) argumentan que la creación de duplicidades en programas, recursos y actividades especializadas lejos de ser ineficiente y dispendiosa es esencial para incrementar la confiabilidad en los proveedores de servicios urbanos.

En la Ciudad de México, las instituciones de vivienda han construido un repertorio de rutinas, incluyendo mecanismos de financiamiento (v.g. enfocados a grupos de bajos ingresos), procedimientos (v.g. coordinación con grupos comunitarios), y políticas (v.g. estabilidad social) que han servido como bases para muchas de las acciones desarrolladas por el programa de renovación habitacional. Las entrevistas en la Ciudad de México (Gamboa, 1995; Eibenschutz, 1995; Stolarski, 1995) confirmaron que muchos de los funcionarios públicos responsables de la instrumentación de las "nuevas" estrategias del RHP trabajaban en realidad para Fonhapo. De hecho, la especialización y la memoria institucional, corporizadas en el personal y las rutinas de Fonhapo, fueron críticas para el éxito subsecuente del RHP.

En Los Ángeles, LADH y HUD instrumentaron un conjunto de rutinas institucionales especializadas (políticas y programas) adecuadas a la naturaleza de la crisis. Esto les ayudó a formular un enfoque para atender efectivamente los problemas de financiamiento de vivienda en los ghost town. El hecho que $85 \%$ de las unidades dañadas en Los Ángeles recibiera financiamiento para su reparación en el curso del primer año después del sismo es una prueba de la efectividad de los programas de reconstrucción; el hecho que las instituciones locales conocieran las condiciones habitacionales y económicas dentro de la ciudad, y pudieran realizar estimaciones puntuales de la magnitud del daño, sirvió para enfocar la reconstrucción hacia la renovación de unidades multifamiliares, y para convencer a HUD de la necesidad de financiamiento especializado.

\section{Adecuación institucional}

La adecuación de una institución se refiere al grado con el que su estructura y sus procesos de toma de decisiones corresponden a los valores y prácticas dominantes en su contexto social. Dos grandes cualidades de la adecuación institucional son: $a$ ) maleabilidad, que es la facilidad con que una institución puede cambiar su forma o su uso de 
manera inmediata, y $b$ ) resistencia, que es la habilidad de una institución para soportar impactos y crisis. Ambas están relacionadas con dos virtudes que tienen gran valor social: la habilidad para responder, y la habilidad para recuperarse.

La adecuación de una institución se apoya en un conocimiento apropiado y oportuno del público al que sirve. Las instituciones de vivienda de la Ciudad de México y Los Ángeles fueron capaces de reorientar sus programas en la medida en que estuvo disponible información de mejor calidad, o en la medida en que fue más precisa la evaluación del daño inicial. El primer decreto de expropiación de la Ciudad de México fue modificado como respuesta al resultado de diagnósticos más completos y a la presión social por enmendar los errores cometidos durante las acciones iniciales. $\mathrm{Al}$ detectarse que entre las propiedades expropiadas había viviendas unifamiliares que no estaban dañadas, y que por lo mismo no debían haber sido incluidas en los programas de reconstrucción, dio pie a una protesta generalizada (Russell, 1985: 8). Este proceso de adaptación y aprendizaje es en gran medida parte de la adecuación institucional.

En realidad, el RHP mismo se convirtió en parte de un proceso de adecuación institucional continua. El programa fue instrumental en la transformación de antiguos arrendatarios en propietarios de sus viviendas. Los paquetes crediticios de Fonhapo fueron ajustados y utilizados para financiar estas viviendas. Tales estrategias fueron aplicadas, probadas, y subsecuentemente se conviritieron en marco de referencia para un programa habitacional de reciente creación en la zona central de la Ciudad de México llamado Casa Propia.

En Los Ángeles, el número inicial de 13 ghost towns se incrementó a 17 una vez que fueron llegando más información y reportes a las instituciones de vivienda. La eficiencia en la recolección de datos, particularmente en términos de definición de crisis y de adecuación institucional, es ilustrada claramente por el Programa Ghost Towns. El sismo de 1994 en Los Ángeles fue el primer gran desastre de Estados Unidos en que fue recopilada y utilizada sistemáticamente en el proceso de reconstrucción una gran cantidad de información (Comerio, 1995). El daño estructural fue de mayor intensidad en la ciudad de Los Ángeles, y la coordinación institucional entre el Departamento de Edificios y Seguridad, y LAHD fue particularmente efectiva, lo que a la postre condujo a la creación de un sistema de información mucho mejor que los que estaban vigentes en las otrasijuridicciones afectadas por el sismo. La disponibilidad de información detallada so- 
bre el número y el tipo de viviendas dañadas, su localización, y las características de las comunidades afectadas, permitió que las instituciones de vivienda en Los Ángeles pudieran enfocarse tanto en la emergencia habitacional como en los programas de recuperación de largo plazo.

\section{Éxito similar, contextos diferentes}

Centralismos versus federalismo

Aunque el orden constitucional en México corresponde a una república federal, históricamente la estructura administrativa y política del país ha sido altamente centralizada. Como consecuencia, esta estructura tiene la capacidad de transformar una crisis local -el terremoto en la Ciudad de México- en un fenómeno nacional. Esta capacidad resulta muy evidente al observar el rol que desempeñaron el presidente de la República, los secretarios de Estado y las dependencias a su cargo en la reconstrucción de vivienda en la Giudad de México. Así, la composición de la Junta de Gobierno del programa RHP refleja el carácter altamente centralizado de los esfuerzos de recuperación y la importancia de las instituciones federales en su instrumentación. Entre sus miembros se encontraban el.jefe del DDF, el titular de la Secretaría de Desarrollo Urbano y Ecología, un representante de la Secretaría de la Contraloría General de la Federación, un subsecretario de la Secretaría de Programación y Presupuesto, el subsecretario de crédito de la Secretaría de Hacienda y Crédito Público, un subsecretario de política interna de la Secretaría de Gobernación, el director general de Banobras y el director general del Fondo para la Vivienda.

Generalmente la estructura política de Estados Unidos es definida como una democracia directa (Herson y Bolland, 1990), cuyos ciudadanos intervienen activamente y cuentan con la capacidad de influir en los procesos políticos. Así, después de sobrevenir una crisis, se esperaría que las organizaciones públicas y comunitarias respondieran directamente a la emergencia para atender necesidades tales como la provisión de alimentos y albergue, y acelerar el restablecimiento de los servicios esenciales. Sin embargo, los esfuerzos de recuperación que siguieron al sismo de 1994 en Los Ángeles se movieron casi en sentido opuesto, ya que su enfoque fue de arriba hacia abajo, con una participación comunitaria casi nula. 
Durante la fase de recuperación, el gobierno federal provee ayuda para la reconstrucción de viviendas e infraestructura pública: FEMA es la agencia federal responsable de coordinar la ayuda federal en casos de emergencia. La Ley Robert T. Stafford para ayuda en casos de emergencia fue aprobada por el Congreso en 1988 y le aseguró a FEMA los recursos y la autoridad necesarios para manejar una situación de crisis de gran escala. Otras instituciones federales también deben proporcionar asistencia durante situaciones de crisis. Por ejemplo, la Administración Federal de Carreteras (FHA por sus siglas en inglés) dispone de fondos para reparar carreteras y puentes que son parte del sistema federal, HUD apoya con fondos de asistencia para vivienda, y el Departamento de Educación ayuda a los distritos escolares localizados en las áreas de desastre. En adición, FEMA puede solicitar a otras agencias federales, tales como el Cuerpo de Ingenieros del Ejército, que auxilien en tareas como la remoción de escombros y la inspección de daños.

Hay dos razones principales para:justificar, tanto en México como en Estados Unidos, este enfoque de arriba-abajo y el rol del gobierno federal en los esfuerzos de recuperación. Financieramente, considerando la destrucción masiva que puede causar un sismo u otro evento similar, las dependencias federales son las instituciones del sector público mejor capacitadas para conjuntar los recursos y la pericia técnica necesarios para establecer y manejar los esfuerzos de recuperación. Políticamente, los poderes Ejecutivo y Legislativo del gobierno federal difícilmente pueden ignorar la devastación causada por las crisis entre sectores importantes de la población, especialmente si esos sectores incluyen comunidades con gran influencia política como es el caso de las poblaciones de la Ciudad de México y Los Ángeles.

\section{Movilización comunitaria}

Después del sismo de 1985, la importancia social y política de la vivienda se hizo evidente. En áreas fuertemente afectadas por los temblores las organizaciones de inquilinos obligaron al gobierno a que hiciera modificaciones sustanciales en sus políticas habitacionales. La movilización popular y la protesta en la Ciudad de México fueron reforzadas por dos factores asociados con la primacía urbana de esta ciudad. Primero, la concentración de instituciones y autoridades nacionales en la Ciudad de México alentó a los grupos sociales a organi- 
zarse y protestar, dado que sus manifestaciones atraerían fácilmente la atención política nacional e internacional. Segundo, como otras ciudades grandes del tercer mundo que enfrentan problemas sociales asociados con la urbanización masiva, la de México tiene una larga historia de organización barrial enfocada en temas como servicios públicos y desarrollo urbano. Otro factor importante, aunque no necesariamente asociado con su primacía, fue la disponibilidad repentina de una gran cantidad de recursos financieros, lo que estimuló que "una montaña completa de organizaciones no gubernamentales aparecieran, porque además había también dinero proveniente de Europa para financiar este tipo de cosas" (Conolly, 1996).

El programa RHP mostró lo que puede lograrse, al menos parcialmente, mediante la movilización y la participación comunitaria. En la medida en que la oposición a los programas del gobierno se fortaleció, los instrumentos formales de política habitacional -especialmente los financieros- adquirieron una nueva importancia estratégica. Debido a que la crisis y la deuda externa hundieron al país en una profunda recesión, la inversión en vivienda se presentó como una de las pocas posibilidades existentes para estimular el crecimiento de la economía. La experiencia de la Ciudad de México también mostró que mediante protestas bien organizadas y de gran escala, la sociedad puede obligar a las instituciones de planeación a tomar acciones radicales. Esto resulta obvio si se advierte que las autoridades mexicanas no sólo construyeron casas nuevas para los pobres, sino que además las subsidiaron.

Por su énfasis en la iniciativa individual, la democracia y la propiedad privada, se podría esperar que las comunidades estadunidenses se hubieran mostrado activas y dispuestas a participar en la toma de decisiones, especialmente de aquellas que pudieran afectar sus viviendas y sus vecindarios directamente, tales como el programa de reconstrucción de Los Ángeles. Sin embargo éste no fue el caso: las comunidades, quizá debido a la falta de recursos financieros y a los bajos niveles de cooperación entre ellas, fueron incapaces de organizarse y tomar la iniciativa en los esfuerzos de recuperación. De hecho, la mayoría de los residentes en los ghost towns abandonó sus propiedades.

La escasa participación comunitaria puede ser explicada por dos factores: la falta de comprensión de la seriedad del problema habitacional en Estados Unidos por parte de los ciudadanos comunes, y la naturaleza fragmentada de las instituciones comunitarias en Los Ángeles. En Estados Unidos la vivienda de interés social, especialmen- 
te para los grupos de bajos ingresos afectados por el sismo, no es un asunto que despierte mucho interés en la opinión pública, ya que está fuera de las prioridades de la mayor parte de las familias de ingreso medio. Para una gran proporción de los estadunidenses la propiedad de una vivienda unifamiliar es la norma. Otro factor en la falta de iniciativa y movilización comunitaria es el alto costo que implica organizarse en una ciudad tan dispersa geográficamente y tan móvil como Los Ángeles. En el pasado, se formaron algunos grupos comunitarios y se movilizaron principalmente con la intención de modificar o detener planes de regeneración urbana ordenados por la ciudad. Por ejemplo, la organización Coalition for Economic Survival defendió los derechos de los inquilinos y se opuso a las estrategias para la regeneración del área de Hollywood; asimismo los abogados de la organización Legal Aid lucharon por los derechos de los residentes pobres del centro de la ciudad amenazados por otro programa municipal de regeneración urbana (Goetz, 1993: 143). De esta manera, aunque ha habido importantes acciones comunitarias, éstas han sido esencialmente defensivas y carentes de coordinación o integración con movimientos sociales más amplios.

\section{Implicaciones de política pública}

Se ha definido una crisis como una situación en la que actores institucionales clave coinciden en que ésta existe, es decir, hay un consenso general entre ellos de que la situación de crisis es real y representa riesgos, y que la falta de acción puede conducir a realidades económicas y políticas aún más severas. La significación y la amenaza constante de una crisis no pueden ser subestimadas, especialmente tratándose de las megaciudades y las instituciones de planeación que intentan manejarlas.

Manejar una situacion de crisis es especialmente complejo en términos de políticas públicas, debido a que los más afectados son generalmente quienes tienen menos recursos, y son también los destinatarios más importantes de las acciones de planeación. Sin embargo, las crisis si son concebidas apropiadamente, pueden ofrecer también oportunidades para la planeación urbana. Las crisis tienden a magnificar tendencias sociales preexistentes, particularmente las relacionadas con el nivel de desigualdad social (Bolin y Stanford, 1991: 32). "Un terremoto como éste", dijo Henry Cisneros, titular de HUD, des- 
pués de terremoto de Los Ángeles, "desnuda la verdad" (citado por Stanfield, 1994: 392). Dos hechos que perturbaron al secretario Cisneros ese día, fueron el gran número de pobres cuyos añejos problemas de vivienda se hicieron evidentes cuando sus casas quedaron destruidas por el sismo, y la grave discriminación residencial que había pasado inadvetida, pero que fue revelada por el desastre. De la misma manera, la amplia discusión y los debates acerca de los impactos de largo plazo del terremoto tuvieron el efecto de crear conciencia pública respecto a que la Ciudad de México vive en un abismo ecológico y es vulnerable no sólo a otros terremotos, sino también a crisis potenciales derivadas de la escasez de agua y la contaminación atmosférica (Kandell, 1988: 574).

Este tipo de encadenamientos temáticos suelen ser promovidos por líderes e instituciones que son persistentes en sus esfuerzos y usan su conocimiento para establecer conexiones entre un asunto y otro. $\mathrm{Pa}$ ra que un tema trascienda una arena debe ser vinculado con otro tema en una segunda arena. En otras palabras, los dos temas necesitan ser colocados en la misma categoría dentro de la estructura de prioridades de la opinión pública. Por ejemplo, los ciudadanos podrán moverse fácilmente de un tema (v.g. los efectos ambientales adversos de la urbanización rápida) al próximo (v.g. el efecto de nueva construcción en los tiempos de evacuación en casos de desastres) debido a que ambos están ligados a la categoría común del crecimiento urbano (Berke y Beatley, 1992: 33-34). Los encadenamientos conllevan también una mejor preparación para crisis futuras: generalmente se perfeccionan los códigos de construcción después de que ocurren desastres como los sismos de las ciudades de México y Los Ángeles. Los códigos más estrictos establecidos después del sismo de Sylmar, California, en 1971, obviamente sirvieron para que algunos edificios no se colapsaran durante el terremoto de 1994 en Los Ángeles, y es lógico esperar que los códigos sean más estrictos después de este último.

Finalmente, las situaciones de crisis ayudan a que las instituciones de planeación se vuelvan más efectivas. El concepto de la mano oculta de Albert Hirshman (1967) tiene implicaciones sutiles y trascendentales para la planeación urbana, así como para el desarrollo institucional, aun a pesar de su simpleza: en el desarrollo de programas nuevos, como los que se aplican durante situaciones de crisis, las instituciones tienden a subestimar las dificultades que enfrentarán, aunque también subestiman su habilidad para superarlas. La mano ocul- 
ta obscurece ambas. En gran medida, esto es algo bueno. Si los problemas fueran valorados en toda su magnitud desde el inicio la gente nunca empezaría a actuar, dado que su capacidad para visualizar soluciones aceptables sería limitada. La mano oculta emplea diferentes estrategias para velar las dificultades. Una es disfrazar los aspectos riesgosos y novedosos de un programa con la idea de que para su ejecución exitosa se requiere solamente la aplicación de un modelo que ya mostró su efectividad (v.g. rutina ) en situaciones diferentes pero similares.

\section{Conclusiones}

El objetivo de este estudio ha sido demostrar el potencial de las rutinas institucionales para la planeación urbana. En mi opinión, iniciativas de gran poder suelen surgir del entendimiento íntimo de las posibilidades de las rutinas para la planeación, algo que resulta de la búsqueda constante de soluciones basadas en su aplicación y transformación acumulativa. Algunos métodos aprendidos mediante la experiencia ayudan a las instituciones de planeación a recorrer este trayecto de descubrimiento más rápidamente. La gran mayoría de las estrategias de planeación son en realidad adaptaciones de soluciones utilizadas previamente. La memoria de las instituciones está llena de este tipo de fórmulas empíricas, y sus operadores conocen muy bien las situaciones para las cuales son apropiadas.

Como ha sido demostrado, la planeación debe ser vista como un proceso que pone a prueba proposiciones acerca de los medios más efectivos para responder a problemas sociales y respecto a los factores que afectan los resultados del curso de acción adoptado; habrá que revaluar y redefinir las respuestas a esos problemas en la medida en que se vaya aprendiendo más acerca de su complejidad. Ciertos experimentos sociales complejos pueden ser parcialmente controlados, pero nunca totalmente; así, los procedimientos institucionales deben ser flexibles y graduales, facilitando la interacción social de manera tal que aquellos grupos más directamente afectados por un problema puedan explorar y procurar objetivos socialmente legítimos (Rondinelli, 1993: 18).

Una manera de manejar la incertidumbre, la complejidad y el cambio en las megaciudades es reconocer que todos los proyectos de planeación son experimentos de política, es decir, concibiéndolos in- 
cremental y adaptativamente mediante la desagregación de los problemas y la formulación de respuestas a través de procesos de decisión que conjuguen aprendizaje y acción. Un enfoque adaptativo permite a los planeadores desarrollar lo que Wildavsky (1979: 15) llama la tarea básica del análisis de políticas públicas: al crear problemas (v.g. rutinizando lo novedoso) que las instituciones sean capaces de manejar con las variables bajo su control, y en el marco temporal disponible. Este enfoque entiende la planeación y la ejecución como el arte de crear problemas que pueden ser resueltos valiéndose de la experimentación informada. El curso de acción adoptado es moldeado por lecciones derivadas de experiencias pasadas, así como por un entendimiento realista de la condiciones imperantes y emergentes.

Finalmente, las experiencia de las ciudades de México y Los Ángeles muestran que la efectividad de las políticas y los programas emprendidos por las instituciones de planeación bajo una circunstancia de crisis urbana probablemente dependió de dos factores. Uno fue la manera en que las instituciones de planeación obtuvieron y movilizaron recursos financieros, materiales y humanos para lograr un crecimiento en la productividad y una ampliación de las oportunidades. El otro fue la forma en que las instituciones de planeación pudieron organizar la formulación y la adecuación de políticas para responder a la creciente complejidad, a la incertidumbre y al cambio de los problemas de desarrollo en ambas megaciudades. Las instituciones de planeación necesitan entender que siendo muy limitada su habilidad para predecir y controlar los resultados de iniciativas de política bajo condiciones de incertidumbre, sus métodos deben ser ajustados para reconocer la incertidumbre y responder mejor para detectar y corregir errores de manera continua, para generar y utilizar conocimientos en la medida en que los experimentos de política progresan, y para modificar las acciones en cuanto aparecen oportunidades y barreras durante su ejecución.

\section{Bibliografía}

Alarcón, Richard (1994), Motion, Los Ángeles, City Council, 20 de mayo.

Berke, Philip y Timothy Beatley (1992), Planning for Earthquakes: Risk, Politics and Policy, Baltimore, The Johns Hopkins University Press.

Bolin, Robert y Lois Stanford (1991), "Shelter, Housing and Recovery: A Comparison of.U.S. Disasters", Disasters, vol. 15, núm. 1, pp. 24-34.

Buchanan, James (1980), "Rent Seeking and Profit Seeking", en James Bu- 
chanan, Robert Tollison y Gordon Tullock (eds.), Toward a Theory of the Rent-Seeking Society, College Station, Texas A. \& M. University Press.

Caiden, Naomi y Aaron Wildavsky (1974), Planning and Budgeting in Poor Countries, Nueva York, Wiley.

Campbell, Tim y David Wilk (1986), "Plans and Plan-Making in the Valley of Mexico: The Evolution of a Planning Process, 1970-1985", Third World Planning Review, vol. 8, núm. 4, pp. 287-313.

Comerio, Mary (1995), "Los Angeles Housing Losses", reporte preparado por la Oficina de Servicios de Emergencia del gobernador de California, Berkeley, Center for Environmental Design Research agosto (mimeo.).

Connolly, Priscilla (1987), "La política habitacional después de los sismos", Estudios Demográficos y Urbanos, vol. 2, núm. 1 (4), pp. 101-120.

(1990), "Housing and the State in Mexico", en Gil Shidlo (ed.), Housing Policy in Developing Countries, Londres, Routledge, pp. 5-32.

(1993), "The Go-Between: CENVI, a Habitat NGO in Mexico City", Environment and Urbanization, vol. 5, núm. 1, pp. 68-90.

_- (colaboradora del Centro de Estudios de la Vivienda y profesora de sociología en la Universidad Autónoma Metropolitana-Unidad Azcapotzalco) (1996), entrevista grabada por el autor, México, 13 de agosto.

Davis, Diane (1991), "Urban Fiscal Crisis and Political Change in Mexico City: From Global Origins to Local Effects", Joumal of Urban Affairs, vol. 13, núm. 2, pp. 175-199.

- (1994), Urban Leviathan: Mexico City in the Twentieth Century, Filadelfia, Temple University Press.

Dunne, Maya (Director of Planning and Policy, Los Angeles Housing Department) (1996), entrevista grabada por el autor, Los Ángeles, 11 de julio (manuscrito).

Earthquake Ghost Town Task Force (1994), Plan to Address Crime and Vandalism Problems at Earthquake "Ghost Towns", memorandum al Ad Hoc Committee on Earthquake Recovery, Los Ángeles, 20 de junio.

(1996), Status of Earthquake Ghost Town Recovery and Security, memorandum al Ad Hoc Committee on Earthquake Recovery, Los Ángeles, 4 de junio.

Ebrard, Marcelo y jorge Gamboa (1991), "Reconstruction in Central Mexico City after the 1985 Earthquakes", Ekistics, vol. 58, núms. 346-347, pp. 18-27.

Eggertsson, Thrainn (1990), Economic Behavior and Institutions, Nueva York, Cambridge University Press.

Eibenschutz, Roberto (ex director general del Fondo Nacional para la Habitación Popular, ex subsecretario de Desarrollo Urbano y Ecología) (1995), entrevista grabada por el autor, Ciudad de México, 25 de julio.

Galster, George et al. (1995), Documentation of LA Earthquake Disaster Housing Assistance Policies and Procedures, reporte preparado para el U.S. Department of Housing and Urban Development, Washington, The Urban Institute, 1 de marzo. 
Gamboa, Jorge (ex director general adjunto del Programa para la Renovación Habitacional Popular, y presidente de la Asociación Mexicana de Arquitectos) (1995), entrevista grabada por el autor, Ciudad de México, 31 de julio.

GAO (U.S. General Accounting Office) (1994), Los Angeles Earthquake: Opinions of Officials on Federal Impediments to Rebuilding, informe para el Congreso, Washington, junio.

Gilbert, Alan (1993), In Search of a Home: Rental and Shared Housing in Latin America, Tucson, The University of Arizona Press.

(1994), The Latin American City, Londres, The Latin American Bureau.

y Ann Varley (1991), Landlord and Tennant: Housing the Poor in Urban Mexico, Londres, Routledge.

Goetz, Edward (1993), Shelter Burden: Local Politics and Progressive Housing Policy, Filadelfia, Temple University Press.

Grindle, Merilee y John Thomas (1991), Public Choices and Policy Change: The Political Economy of Reform in Developing Countries, Baltimore, The Johns Hopkins University Press.

Gruel, Wendy (Southern California Representative, U.S. Department of Housing and Urban Development, Los Ángeles) (1996), entrevista grabada por el autor, Los Ángeles, 21 de marzo.

Herson, Lawrence y John Bolland (1990), The Urban Web: Politics, Policy and Theory, Chicago, Nelson-Hall Publishers.

Hirschman, Albert (1967), Develapment Projects Observed, Washington, The Brookings Institution.

HUD (U. S. Department of Housing and Urban Development) (1994), Early Observations on HUD's Los Angeles (Northridge) Earthquake Disaster. Response, Washington, Office of Policy Development and Research. (1995a), Preparing for the Big One: Saving Lives Through Earthquake Mitigation in Los Angeles, Califormia, Office of Policy Development and Research, Washington.

- (1995b), "CDBG: Making a Difference in America's Communities", $R \boldsymbol{e}$ cent Research Results, Office of Policy Development and Research, agosto, pp. 1-3.

- (1996), "HOME Helps Low-Income Households, Says Evaluation", Recent Research Results, Office of Policy Development and Research, mayo, p. 4.

INEGI (1992a), Ciudad de México (área metropolitana): Resultados definitivos. Tabulados básicos: XI Censo general de población y vivienda, 1990, Aguascalientes, Instituto Nacional de Estadística, Geografía e Informática.

- (1992b), Anuario estadístico de los estados mexicanos. Edición 1991, Aguascalientes, Instituto Nacional de Estadística, Geografía e Informática.

Johnson, William (1989), The Politics of Urban Planning Nueva York, Paragon House.

Kandell, Jonathan (1988), La Capital: The Biography of Mexico City, Nueva York, Random House. 
Krueger, Anne (1974), "The Political Economy of the Rent-Seeking Society", American Economic Review, vol. 64, núm. 3, pp. 291-303.

LAHD (Los Angeles Housing Department) (1994), Earthquake Recovery: Housing Update, agosto.

(1995), "Los Angeles Housing Department Report on the Earthquake Recovery Program and Prioritization Plan per the Alarcon/Hernandez Motion (C.F. 95-0073)", Committee Transmittal to Mayor Richard Riordan, 20 de noviembre (mimeo.).

(1996), "Rebuilding Communities after the 1994 Northridge Earthquake: Year Two Recovery Report”, Los Ángeles, Los Angeles Housing Department, 17 de enero (mimeo.).

Lane, Jan-Erik (1993), The Public Sector: Concepts, Models and Approaches, Londres, Sage.

Lin, Justin y Jeffrey Nugent (1995), "Institutions and Economic Development", en Jere Behrman y T. N. Srinivasan (eds.), Handbook of Development Economics, vol. 3A, Amsterdam, Elsevier Science B.V, pp. 2301-2370.

Linden, Eugene (1993), "Megacities”, Time, vol. 141, núm. 2, pp. 28-38.

March, James y Johan Olsen (1984), "The New Institutionalism: Organizational Factors in Political Life", The American Political Science Review, vol. 78, núm. 3, pp. 734-749.

(1989), Rediscovering Institutions: The Organizational Basis of Politics, Nueva York, The Free Press.

Martin, Hugo (1994), "Loans to Rebuild Quake 'Ghost Towns' Okd", Los Angeles Times, 23 de julio .

- (1995), "99\% of 'Ghost Town' Owners Get Quake Aid", Los Angeles Times, 22 de noviembre.

Meislin, Richard (1985), "After the Quakes: Political Rumblings", The New York Times, 4 de octubre.

Mydans, Seth (1994), "Months after the Quakes Ghost Towns in the City of Angels", The New York Times, 10 de agosto.

Neal, David y Brenda Phillips (1995), "Effective Emergency Management: Reconsidering the Bureaucratic Approach", Disasters, vol. 19, núm. 4, pp. 327-337.

Niskanen, William (1971), Bureaucracy and Representative Government, Chicago, Aldine.

Perló, Manuel (1991), "La política habitacional y sus implicaciones para el mercado de bienes raíces del centro de la Ciudad de México", ponencia presentada en el IX Encuentro de la Red Nacional de Investigación Urbana, México, octubre (mimeo.).

RHP (Renovación Habitacional Popular) (1988), Memoria de la reconstrucción, México, Renovación Habitacional Popular (mimeo.).

Riding, Alan (1986), "A Year after Quake, Mexico City is on the Mend", The New York Times, 20 de septiembre.

Rohter, Larry (1987), "Mexico Quake Victims Try to Forget", The New York Times, 21 de septiembre. 
Rondinelli, Dennis (1993), Development Projects as Policy Experiments: An Adaptive Approach to Development Administration, $2^{\mathrm{a}}$ edicion, Londres, Routledge.

Russell, George (1985), "Trouble after an Earlier Disaster", Time, 25 de noviembre.

Scott, W. Richard (1995), Institutions and Organizations, Thousand Oaks, Sage.

Schneekloth, Lynda y Robert Shibley (1995), Placemaking: The Art and Practice of Building Communities, Nueva York, John Wiley and Sons.

Self, Peter (1982), Planning the Urban Region: A Comparative Study of Policies and Organizations, University of Alabama Press.

Selznick, Philip (1992), The Moral Commonwealth: Social Theory and the Promise of Community, Berkeley, University of California Press.

Squier, Gary (1992), "Letter from Los Angeles to the Honorable Tom Bradley, Mayor, City of Los Angeles", Los Ángeles, Housing Preservation and Production Department, 14 de enero (mimeo.).

(1993), "Letter from Los Angeles to the Honorable Tom Bradley, Mayor, City of Los Angeles", Los Ángeles, Housing Preservation and Production Department, 20 de enero (mimeo.).

Stanfield, Rochelle (1994), "For Some, the Waiting is Nothing New", National Journal, vol. 26, núm. 7.

Stockton, William (1986), "Long Wait Ending for Mexico Quake Victims", The New York Times, 3 de agosto.

Stolarski, Noemi (ex colaboradora de la Coordinación de Investigación e Integración del Documento de Renovación Habitacional Popular y ex colaboradora del Fondo Nacional para la Habitacion Popular) (1995), entrevista grabada por el autor, Ciudad de México, 1 de agosto.

Tullock, Gordon (1965), The Politics of Bureaucracy, Washington, Public Affairs Press.

U.S. Department of Commerce. Bureau of the Census (1992), 1990 Census of Population and Housing: Summary Social, Economic, and Housing Characteristics: United States (1990 CPH-5-1), Washington, Government Printing Office.

Wildavsky, Aaron (1979), Speaking Truth to Power: The Art and Craft of Policy Analysis, Boston, Litde Brown, and Company. 